\title{
comentarios bibliográficos
}

sobre estas películas que constituyen un legado de obligado conocimiento. Sólo queda que las nuevas generaciones de cinéfilos redescubran, a través de sus páginas, la obra de Lewton con los ojos

\section{LOZANO BARTOLOZZI, Ma. del Mar (dir.): Plástica Extremeña, Badajoz, Fundación Caja Badajoz, 2008}

\section{Francisco Sanz Fernández Universidad de Extremadura}

Hace ahora dieciocho años, la Catedrática de Historia del Arte de la Universidad de Extremadura $\mathrm{M}^{\mathrm{a}}$ del Mar Lozano Bartolozzi encabezaba y dirigía una investigación titulada Plástica Extremeña, que resultó muy útil para el conocimiento y la difusión de las manifestaciones artísticas realizadas en lo que hoy comprenden las tierras de Extremadura, antaño Lusitania, koras de la Marca Media de al-Andalus o las Extremaduras, por encargo de la Fundación Caja de Badajoz. Desde la prehistoria a las últimas manifestaciones artísticas de los noventa, aquella obra compilaba una suerte de obras y compendiaba a un grupo de artistas, muchos de ellos anónimos para el público más erudito, que recuperaban así un lugar entre la plástica extremeña y nacional.

Llegados a 2008, la mayor parte del equipo que trabajó en aquella investigación y otros que se han sumado espantados por un renovado sentimiento de horror. Quizá entonces, como un eléctrico chasquido, vuelvan a sentir un largo y lento escalofrío recorriéndoles, de norte a sur, toda la geografía del espinazo.

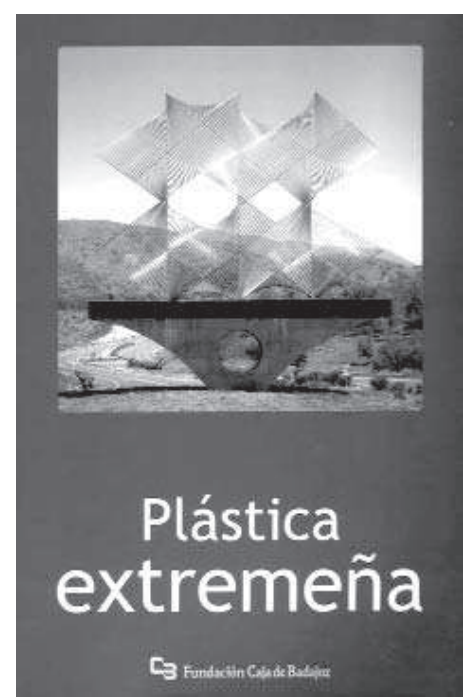

ahora, conforman un elenco de expertos en las distintas materias que han participado de nuevo en la reedición, actualización y puesta al día de aquella obra, bajo el patrocinio nuevamente de la Fundación Caja de Badajoz. La doctora Cruz Villalón y los doctores Bazán de Huerta, Sánchez Lomba y Méndez Hernán, profesores del Departamento de Arte y Ciencias del Territorio de la Uex., además de la doctora $\mathrm{M}^{\mathrm{a}}$ Jesús Ávila, que tras su trabajo como conservadora en el Museo del Chiado de Lisboa y en la colección de la Caixa Geral de Depósitos de la misma ciudad 


\section{Q: comentarios bibliográficos}

portuguesa, es en la actualidad la Coordinadora de la Fundación Helga de Alvear en Cáceres, y de Javier Cano, Director del Centro de Conservación y Restauración de Bienes Culturales de la Junta de Extremadura. Para lo cual se han revisado los contenidos con el fin de tener presente los avances arqueológicos y científicos de las dos últimas décadas, en las que han visto la luz numerosas publicaciones que han despejado dudas y añadido conocimientos. Es decir, se ha vuelto a concebir el libro como el estudio de un conjunto de obras relevantes y monografías de artistas dedicados principalmente a la pintura, la escultura y otras manifestaciones, como las artes musivarias o el grabado; artistas oriundos de Extremadura, aunque no vivieran en la región, o que aún no siendo extremeños han trabajado cierto tiempo en ella.

Y con la misma ordenación hecha por capítulos, desde la Antigüedad a la etapa contemporánea, y dentro de ellos siguiendo una secuencia cronológica en los primeros y una ordenación alfabética por autores a partir de la Baja Edad Media. Basado también en que un elemento fundamental son las imágenes de las obras, pues la fuerza de estas radica en gran parte en el poder de atracción, complicidad y enigma que generan en el que las contempla.

El libro, de 743 páginas y con un total de 280 monografías de obras o autores y cinco estudios generalistas, además de una bibliografía especializada, se inicia con una visión de las primeras manifestaciones, la prehistoria, con documentos desde el Paleolítico en la cueva de Maltravieso (Cáceres) hasta los hallazgos arqueológicos de la protohistoria, rozando la civilización romana. Se ha intentado integrar cada documento en su contexto de la vida humana, en una selección de yacimientos o piezas representativas, que puedan significar la distinta expresión de cada una de las etapas culturales de esta larga fase. Se señalan nuevas aportaciones en este campo, como las incisiones del Molino Manzánez, entre los términos de Cheles y Alconchel, y se insiste en reconocidos objetos de gran valor patrimonial, como el Tesoro de Aliseda, que representa un conjunto clave del arte orientalizante de la península.

La riqueza de la cultura romana en Extremadura ha permitido trazar una completa visión de los distintos géneros y tendencias de su plástica a lo largo de todo el Imperio, a través de piezas significativas, y su distinta estética, dependiendo de momentos o contextos. Mérida, centró los talleres de creación en el territorio de la Lusitania, pero la expansión del arte, a través de las ciudades y villas, ofrece una diseminación de testimonios por toda la geografía extremeña. Nuevos hallazgos, entre los que destacan las investigaciones del foro de Emerita Augusta y la adición del llamado foro de mármol, que conmemoraba a Augusto, o la escultura thoracata en bronce dorado que testimonia manifestaciones de una escultura pública de categoría en la colonia Norba Caesarina (Cáceres), cuentan entre las novedades que se aportan a la anterior edición.

En cuanto a la etapa visigótica e hispanomusulmana, se aportan algunas piezas más, que enriquecen este perío- 


\section{comentarios bibliográficos}

do oscuro, particularmente en la vertiente del Islam, que cuenta con escasos testimonios plásticos en Extremadura.

En lo que respecta a los capítulos correspondientes entre los siglos XV y XVIII, de los siglos del último Gótico al Neoclasicismo, se han revisado y ampliado considerablemente las biografías de artistas de la primera edición, y añadido cuarenta nuevas monografías que, en el conjunto de los capítulos precitados, equivale al $50 \%$ de lo que en su momento se publicó. Se han incluido nuevas entradas referidas a arquitectos, entalladores, ensambladores, pintores y maestros doradores y policromadores; atendiendo tanto a su trayectoria artística como al contexto en el que se produce su obra.

Asimismo, se ha buscado analizar las piezas artísticas desde todos los enfoques metodológicos que ofrece la historiografía: sociológico, económico, formal, incidiendo en cuestiones tan interesantes como los modelos y repertorios iconográficos, es decir, las láminas de grabados en las que se inspiraron artistas como el pintor placentino Pedro de Mata o el universalmente conocido Francisco de Zurbarán. Además de esto, se ha intentado mostrar todas las facetas que un artista dedicado a trabajar a la madera reunía en su taller, reproduciendo diversos tipos de obra para que el público pueda acercarse con mayor facilidad a nuestro pasado artístico.

Aparte de actualizar el siglo XIX más complicada ha sido la tarea de reflexionar sobre el arte de los siglos XX y XXI. Y sobre los nuevos medios artísticos y los nuevos conceptos del arte; lo que ha conducido a este magnífico grupo de trabajo a reunir autores que no fueran solamente pintores y escultores, sino también de artes performativas como el happening o la propia performan, además del cómic o la historieta, la ilustración de libros, el videoarte, el netart, la poesía visual, o la fotografía, medio trabajado independientemente o con mestizajes de otros géneros, que ha sido tratado en uno de los estudios generalistas posteriores pero también a través de algunos autores incluidos en las monografías. Así junto a Barjola, Naranjo, Vostell o Luis Canelo, encontramos a Javier Alcaíns, Genín Andrada o Maite Cajaraville.

Además los antiguos Apéndices han sido sustituidos por lo que los autores de la obra han dado en llamar "Estudios": dedicados al análisis de la platería, las artes suntuarias o a estudiar las obras que dejaron en nuestra tierra artistas foráneos y a la fotografía.

En lo que respecta al capítulo de las artes suntuarias, en éste se analizan los bordados y miniados de Guadalupe, así como el arte de la rejería, azulejería y tapices. $Y$ al referirse a los "Artistas foráneos en colecciones extremeñas. La contemporaneidad", han querido mencionar las importantes colecciones de arte contemporáneo que albergan instituciones, fundadas o relanzadas después de los años noventa como, el MEIAC de Badajoz, el Museo de Cáceres o el Museo Vostell Malpartida.

La obra, en palabras de su directora, «ha sido elaborada por un equipo con una profesionalidad siempre honesta, aunque pueda ser discutida, pues 


\section{Q: comentarios bibliográficos}

siempre se ha optado por la selección de autores con sólida trayectoria, aunque sea todavía corta en el tiempo en algunos casos. También nos hemos permitido la diversidad de espacios dedicados a artistas y obras, sin someternos a demasiados patrones o modelos de fichas que estarían lejos de la finalidad de un libro como éste».

Para la realización de esta obra enciclopédica de las artes plásticas extreme-

\section{LLAMAZARES RODRIGGUZ, Fernando: Fuentes docu- mentales para el Arte Barroco en la provincia de León. Ensambladores, Escultores y Pintores, León, Universidad, 2008}

\section{Juan Antonio Sánchez López Universidad de Málaga}

A nadie escapa cómo la cultura del Barroco podría ser comparable, en sentido figurado, a una piedra preciosa cuyas superficies han sido talladas con precisión en una gran variedad de facetas. Al ser 'heridas' por la luz, esas 'caras' se muestran proclives a destilar una infinitud de iridiscencias capaces de convertir lo único en múltiple y lo múltiple en único. Aplicado al objeto de estudio, la metáfora no puede esconder otra intención que la de sugerir al estudioso la conveniencia de someter las capacidades de interpretación y análisis de los objetos y realidades de una época tan compleja a los dictados de unos enfo ñas, se ha contado con la colaboración de una diversidad de instituciones, públicas y privadas empezando por la Consejería de Cultura y Turismo de la Junta de Extremadura, diversos museos extremeños y nacionales, Patrimonio Nacional, el Real Monasterio de Santa María de Guadalupe, los cabildos catedralicios y las parroquias de las diversas diócesis extremeñas.

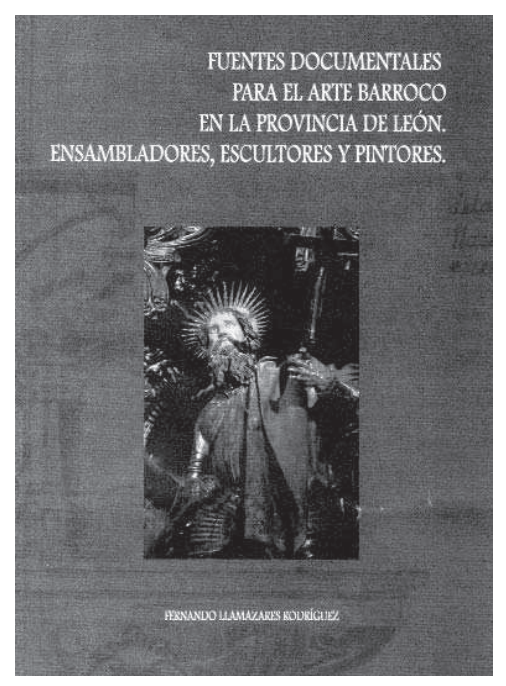

ques tan versátiles como poliédricos.

Qué duda cabe que las fuentes documentales constituyen una herramienta capital para la feliz consecución de tales objetivos, aunque no siempre coincidan las maneras o los criterios tenidos en cuenta a la hora de ofrecerlas al conocimiento del estudioso o el lector en general. Es a propósito de esta cuestión, por lo que resulta especialmente 